\title{
Oral Administration of Polyphenolic Compounds from Cognac Decreases ADP-Induced Platelet Aggregation and Reduces Chronotropic Effect of Isoprenaline in Rats
}

\author{
N. CARUSIO ${ }^{1,2}$, R. WANGENSTEEN ${ }^{1}$, A. FILIPPELLI ${ }^{2}$, R. ANDRIANTSITOHAINA ${ }^{1}$ \\ ${ }^{1}$ CNRS UMR 6214-INSERM 771, Faculté de Médecine, Rue Haute de Reculée, 49045 Angers \\ cedex France and ${ }^{2}$ Seconda Università di Napoli, Dipartimento di Medicina Sperimentale, via \\ Costantinopoli, 16, Napoli, Italia
}

Received July 27, 2006

Accepted June 18, 2007

On-line July 26, 2007

\begin{abstract}
Summary
This study sought to evaluate whether consumption of polyphenol extract from Cognac (CPC) modulates platelet activation and cardiovascular reactivity in rats. Male Wistar rats were treated daily for 4 weeks by intra-gastric gavage receiving CPC at $80 \mathrm{mg} / \mathrm{kg} /$ day or vehicle (5\% glucose). Platelet adhesion and aggregation in response to different activators were assessed. Cardiac and vascular reactivity in response to various agonists as well as NO measurement by electron paramagnetic resonance technique were investigated in isolated heart and thoracic aorta. Oral administration of CPC decreased platelet aggregation induced by ADP but not by collagen. CPC did not affect adhesion to collagen. The chronotropic but not the inotropic response to isoprenaline was reduced without alteration of NO production in hearts from CPC-treated rats. CPC treatment did not affect ex vivo relaxation to acetylcholine nor NO content of rat aorta. CPC did not significantly alter the response to phenylephrine in aorta despite the participation of endothelial vasoconstrictor products. In summary, chronic treatment with CPC has no impact on ex vivo vascular and cardiac reactivity; however, it reduced heart work and platelet aggregation. These data suggest the existence of compounds in Cognac that may decrease the risk of coronary thrombosis and protect against some cardiac diseases.
\end{abstract}

\section{Key words}

Cognac • Polyphenols • Platelet aggregation - Isoprenaline • Nitric oxide

\section{Corresponding author}

R. Andriantsitohaina, CNRS UMR 6214-INSERM 771, Faculté de Médecine, Rue Haute de Reculée, 49045 Angers, cedex France. E-mail: ramaroson.andriantsitohaina@univ-angers.fr

\section{Introduction}

The regular and moderate consumption of alcoholic beverages including Cognac has been already described to decrease the risk of cardiovascular diseases, possibly due to ethanol content (Rimm et al. 1991, Carando et al. 1998). However, epidemiological studies reported that some beverages such as red wine, might impact mortality more favorably than other alcoholic beverages (Renaud and De Lorgeril 1992). The beneficial property of red wine could be attributed to the presence of polyphenols (Rotondo et al. 2000). Mechanisms that have been proposed to explain the prevention of cardiovascular diseases by polyphenols include reduced oxidation of low-density lipoprotein, inhibition of platelet aggregation and neutrophil adhesion. Polyphenols have also been reported to affect the activity of enzymes critically involved in pathways regulating cell proliferation and activation (for reviews see Curin and Andriantsitohaina 2005, Perez-Vizcaino et al. 2006). We have previously shown that polyphenols from red wine (RWPC) were able to produce ex vivo endotheliumdependent relaxation in rat aortic rings by enhanced nitric oxide (NO) synthesis (Andriambeloson et al. 1997, 1998). In addition, short-term oral administration of RWPC produced a decrease in blood pressure in normotensive rats associated with an augmentation of endothelium-dependent relaxation (Diebolt et al. 2001). Finally, we provided evidence that Provinols ${ }^{\mathrm{TM}}$, another source of RWPC, partially prevents hypertension, cardiovascular remodeling and vascular dysfunction via 
the increase of NO-synthase activity and inhibition of oxidative stress (Pecháňová et al. 2004).

Cognac belongs to alcoholic beverages rich in polyphenols and moderate consumption may have potential beneficial effects on health. Indeed, Cognac and its phenolic constituents have already been described to be antioxidant (Goldberg et al. 1999, Da Porto et al. 2000). Quantitatively, the most important phenolic constituent in this beverage is ellagic acid. This compound possesses antimutagenic and anticancer properties (Josephy et al. 1990) as well as in vitro and in vivo antioxidative effects (Majid et al. 1991).

Several studies demonstrated that polyphenols inhibit platelet aggregation and improve endothelial function (for review see Vita 2005, Perez-Vizcaino et al., 2006). Recently, non-alcoholic polyphenolic extract from Armagnac, with qualitatively similar polyphenols found in Cognac, has been found to inhibit ADP-induced platelet aggregation in vitro (Umar et al. 2005). Moreover, we have previously reported that Cognac polyphenolic compounds (CPC) induce vasorelaxation in vitro and decrease infarct size subsequent to ischemiareperfusion (Ralay Ranaivo et al. 2004). The present study was aimed to test the hypothesis that long-term oral administration of a non-alcoholic polyphenolic extract of CPC affects platelet aggregation, vascular reactivity to noradrenaline and acetylcholine in aortic rings and contraction force developed by isolated hearts. Finally, the hypothesis that CPC treatment alters aortic and cardiac production of $\mathrm{NO}$ was also investigated.

\section{Methods}

\section{Oral administration of $C P C$}

Two groups of 10 male Wistar, rats (250-300 g) were treated daily for 4 weeks by intra-gastric gavage: the first group (control) received the vehicle (5\% glucose) and the second group received CPC at $80 \mathrm{mg} \mathrm{kg}^{-1}$ day $^{-1}$. Blood was taken $24 \mathrm{~h}$ after the last dose of the treatment to study platelet adhesion and aggregation. Thoracic aorta and hearts from one half of the rats were isolated to study vascular and cardiac reactivity, and for NO measurements. Hearts from the other half of the rats were used for cardiac studies.

\section{Platelet aggregation}

Blood anticoagulated with acid-citrate-dextrose solution (1/6 blood volumes) was centrifuged at $1570 \mathrm{~g}$ for $2 \mathrm{~min}$ at $37^{\circ} \mathrm{C}$, after which the upper platelet-rich plasma phase was removed and centrifuged at $1570 \mathrm{~g}$ for $15 \mathrm{~min}$. The platelet pellet was washed twice in Tyrode's buffer in mM: $\mathrm{NaCl} 137, \mathrm{KCl} 2, \mathrm{NaHCO}_{3} 12, \mathrm{NaH}_{2} \mathrm{PO}_{4}$ $0.3, \mathrm{CaCl}_{2} 2, \mathrm{MgCl}_{2}$ 2, glucose 5.5, HEPES 5, pH 7.3, containing $0.35 \%$ bovine serum albumin as previously described (Cazenave et al. 1983). Finally, it was resuspended at $2.5 \times 10^{5}$ platelets $\mu l^{-1}$ in the same buffer, in the presence of $0.02 \mathrm{U} / \mathrm{ml}$ of the ADP scavenger apyrase (adenosine 5'-triphosphate diphosphohydrolase), a concentration sufficient to prevent desensitization of platelet ADP receptors during storage. This preparation of washed platelets was kept at $37{ }^{\circ} \mathrm{C}$ and used for platelet adhesion and aggregation experiments.

Platelet aggregation was studied using an aggregometer Chronolog Corporation ${ }^{\mathrm{TM}}$. A volume of $225 \mu \mathrm{l}$ of the platelet suspension was placed in a glass turbidity tube and warmed at $37^{\circ} \mathrm{C}$. Three minutes later, $25 \mu \mathrm{l}$ of agonists solution was added to obtain a final concentration of ADP equal to $1,2.5$ and $5 \mu \mathrm{M}$ or collagen equal to $25 \mu \mathrm{g} \mathrm{ml}^{-1}$. The extent of aggregation was estimated by the percent of maximum increase in light transmission, with the buffer representing $100 \%$ transmittance.

\section{Platelet adhesion to fibrillar collagen}

Ex vivo platelet adhesion was carried out as described by Cazenave et al. (1983). Briefly, washed platelets samples were incubated in duplicate in the same aggregometer at $37{ }^{\circ} \mathrm{C}$ and stirred at $900 \mathrm{rpm}$. EDTA $(5 \mathrm{mM})$ was added to prevent platelet aggregation. After $5 \mathrm{~min}$, collagen $\left(50 \mu \mathrm{g} \mathrm{ml}^{-1}\right)$ was added and the samples were stirred for a further $15 \mathrm{~min}$. Platelets were counted optically using a Bürker chamber, before and 15 min after collagen addition and a difference in platelet count was taken as an index of their adhesion to collagen.

\section{Isolated perfused heart}

Rats were anesthetized with pentobarbital (60 $\mathrm{mg} \mathrm{kg}^{-1}$, i.p.) and the heart was rapidly excised and placed in ice-cold Krebs-Henseleit buffer with the following composition in mM: $\mathrm{NaCl} 118, \mathrm{NaHCO}_{3} 24$, $\mathrm{KCl} 4.7, \mathrm{KH}_{2} \mathrm{PO}_{4} 1.2, \mathrm{MgSO}_{4} 1.2, \mathrm{CaCl}_{2}$ 1.7, glucose 10, gassed with $95 \% \mathrm{O}_{2}, 5 \% \mathrm{CO}_{2}$ and maintained at $37{ }^{\circ} \mathrm{C}$. Then, the heart was immediately mounted and cannulated in the retrograde mode according to Langendorff method as previously described (Gyorgy et al. 1999). Transducers were connected to a computer via an amplifier and a $\mathrm{MacLab}^{\mathrm{TM}}$ (ADI Castle Hill, Australia) for online recording and analysis of parameters. Cardiac parameters 
(heart rate, contraction force) were recorded continuously. Concentration-response curves to isoprenaline were constructed to study the inotropic and chronotropic effects.

\section{Aortic preparations and mounting}

Thoracic aorta was removed, carefully cleaned of adhering fat and connective tissue and cut into rings (2-3 mm length). Aortic rings were mounted on myographs filled with a physiological salt solution (PSS) with the following composition in $\mathrm{mM}$ : $\mathrm{NaCl} 118, \mathrm{KCl}$ 4.8, $\mathrm{CaCl}_{2}$ 2.5, $\mathrm{MgSO}_{4}$ 1.2, $\mathrm{KH}_{2} \mathrm{PO}_{4}$ 1.2, $\mathrm{NaHCO}_{3} 24$, glucose 11 , at $37{ }^{\circ} \mathrm{C}$ and bubbled with a $95 \% \mathrm{O} 2,5 \%$ $\mathrm{CO}_{2}$ mixture, under normalized tension as previously described (Diebolt et al. 2001). In some experiments, the endothelium was removed by gentle rubbing of the intima of the ring with curved forceps. The presence of functional endothelium was assessed in all preparations by determining the ability of acetylcholine $(1 \mu \mathrm{M})$ to induce more than $50 \%$ relaxation of rings precontracted with noradrenaline $(1 \mu \mathrm{M})$. The absence of relaxation to acetylcholine indicates that the vessels were functionally denuded of their endothelium. Concentration-response curves to noradrenaline were constructed in a cumulative manner in aorta with or without functional endothelium to study vascular contraction. Endothelium-dependent relaxation was studied in thoracic aorta with and without functional endothelium and precontracted to approximately $80 \%$ of maximal tension with noradrenaline. Acetylcholine was applied in a cumulative fashion.

NO spin-trapping and electron paramagnetic resonance (EPR) spectroscopy

The NO content of aortic rings (6-8 mm length) and heart slices was assayed as described by Alencar et al. (2003) after formation of the paramagnetic adduct $\mathrm{Fe}(\mathrm{II}) \mathrm{NO}(\text { diethyldithiocarbamate })_{2}$ ([Fe(II)NO(DETC) $\left.)_{2}\right]$ ) detectable by EPR in rings treated for $30 \mathrm{~min}$ at $37{ }^{\circ} \mathrm{C}$ with $0.5 \mathrm{mM}\left[\mathrm{Fe}(\mathrm{II})(\mathrm{DETC})_{2}\right]$ complex as colloid (Kleschyov et al. 2000). Tissues were frozen in liquid nitrogen until EPR measurements. EPR spectra were recorded on a MS100 spectrometer (Magnettech, Berlin, Germany) under the following conditions: temperature, $77 \mathrm{~K}$; microwave frequency, $9.34 \mathrm{GHz}$; microwave power, $20 \mathrm{~mW}$; modulation frequency, $100 \mathrm{kHz}$; modulation amplitude, $0.5 \mathrm{mT}$; and time constant, 100 ms. After EPR measurements, the tissue samples were dried and weighted. The relative $\left[\mathrm{Fe}(\mathrm{II}) \mathrm{NO}(\mathrm{DETC})_{2}\right]$ concentrations ( $A W_{\mathrm{ds}}{ }^{-1}$ ) were determined dividing the third component amplitude $(A)$ of the three-lines EPR signal by the weight of the dried sample $\left(W_{\mathrm{ds}}\right)$.

\section{Expression of results and statistical analysis}

The extent of platelet aggregation was estimated quantitatively by measuring the maximum curve height above baseline level and expressed as percentage of light transmission. Cardiac parameters were monitored continuously and included contraction force in gram and heart rate in beats per minute (bpm) and expressed as percentage of basal values. Vascular contraction was expressed in gram and the relaxation was expressed as percentage of the decrease in the level of precontraction. The NO content was expressed in relative $\left[\mathrm{Fe}(\mathrm{II}) \mathrm{NO}(\mathrm{DETC})_{2}\right]$ concentrations $\left(A W_{\mathrm{ds}}{ }^{-1}\right)$.

All results are expressed as mean \pm S.E.M. of $n$ experiments, where $n$ represents the number of rats. Analysis of variance and Student's unpaired $t$-test were used for statistical analysis. $P<0.05$ value was considered significant.

\section{Drugs}

The enriched and lyophilized CPC powder was provided by the "Bureau Interprofessionel du Cognac" with the following composition in $\mathrm{mg} \mathrm{g}^{-1}$ of powder: gallic acid 2.28, ellagic acid 15.17, 5-hydroxymethylfurfural 2.11, furfural 0.35 , vanillic acid $0.30,5$ methylfurfural 0.17 , syringic acid 0.74 , vanillin 0.45 , syringaldehyde 2.02 , scopoletin 0.03 , coniferaldehyde 2.35 , sinapaldehyde 8.21 . The total polyphenols content was about $48.8 \%$, determined by colorimetric FolinCiocalteau method using gallic acid as standard. All drugs were from Sigma Chemical (Grenoble, France).

\section{Results}

\section{Platelet aggregation and adhesion}

As illustrated in Figure 1a, ADP induced platelet aggregation in concentration-dependent manner from 1 to $5 \mu \mathrm{M}$. Interestingly, platelet taken from rats treated with Cognac displayed lower response to ADP. The reduced response to ADP was significantly different at 2.5 and 5 $\mu \mathrm{M}$ when compared to the response obtained in platelets from control rats $(\mathrm{P}<0.05)$. In contrast to ADP, CPC treatment did not affect platelet aggregation when collagen (25 $\mu \mathrm{g} \mathrm{ml}^{-1}$ ) was used as agonist (Fig. 1b). Furthermore, adhesion response to fibrillar collagen was the same in the two groups (Fig. 1c). 
(a)

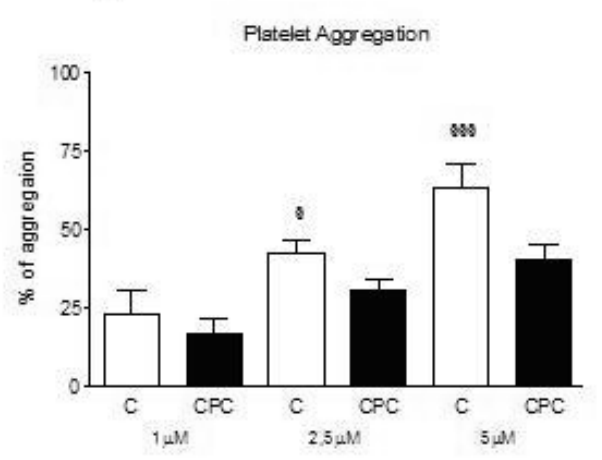

(b)

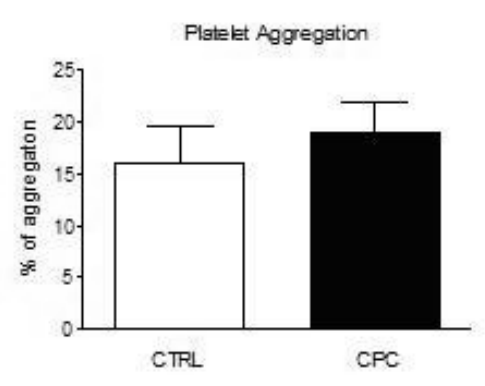

(a)

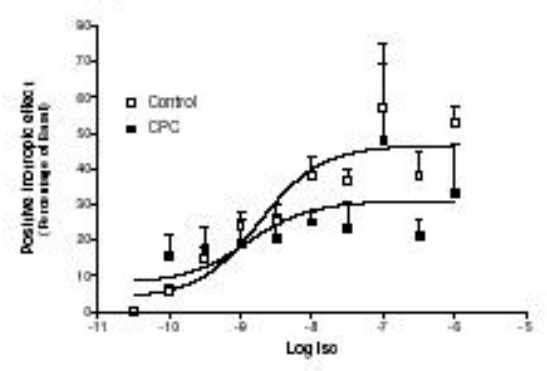

(c)

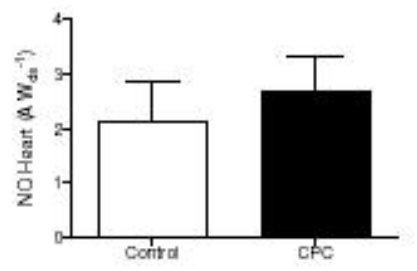

(c)

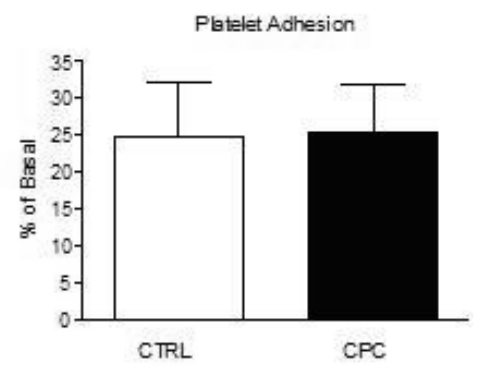

(b)

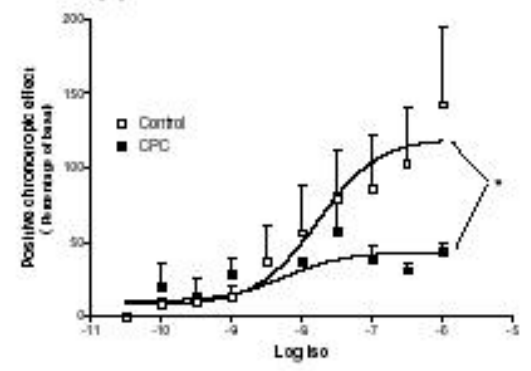

Fig. 1. Effects of cognac polyphenolic compounds (CPC) on platelet aggregation and adhesion. Percentage of platelet aggregation with ADP (1, 2.5 and $5 \mu \mathrm{M}(n=4)$ (a). Platelet aggregation and adhesion with collagen $\left(25 \mu \mathrm{g} \mathrm{ml}^{-1} ; 50 \mu \mathrm{g} \mathrm{ml}{ }^{-1}\right.$ respectively $n=5)$ (b and c) Aggregation and adhesion data are presented as mean \pm S.E.M. (* $\mathrm{P}<0.05$, *** $\mathrm{P}<0.001$ significantly different compared to response to $\operatorname{ADP}(1 \mu \mathrm{M}),+\mathrm{P}<0.05$ Control vs CPCtreated rats); $n$ represents the number of rats.

Fig. 2. Effects of cognac polyphenolic compounds (CPC) on cardiac reactivity. Control $(\boldsymbol{m} ; n=5)$ and CPC treated $(\square ; n=6)$ hearts were perfused in Langendorff mode. Changes in contractile force (a) and heart rate (b) in response to increasing concentrations of isoprenaline (Iso) are shown as percentage of baseline. NO content of heart measured by EPR in control $(\square ; n=5)$ and CPC-treated rats $(\mathbf{\square} ; n=5)(\mathbf{c})$. Data are presented as mean \pm S.E.M. $\quad(* P<0.05)$, $n$ represents the number of rats.
Effect of CPC on cardiac reactivity to isoprenaline and heart NO content

At $24 \mathrm{~h}$ after the end of treatment, cardiac parameters were recorded in isolated hearts from the two groups of rats. The basal forces and heart rate were $0.996 \pm 0.06 \mathrm{~g}$ and $1.7 \pm 0.28 \mathrm{~g}$, and $118.4 \pm 33.8 \mathrm{bpm}$ and $211.6 \pm 39.8 \mathrm{bpm}$ for hearts from control and CPC- treated rats, respectively. Isoprenaline produced concentration-dependent increase in force and heart rate (Fig. 2). The positive inotropic effect of isoprenaline was not significantly different in hearts from the two groups of rats (Fig. 2a). However, the positive chronotropic effect induced by isoprenaline was significantly reduced $(\mathrm{P}<0.05)$ in hearts from $\mathrm{CPC}$ - 


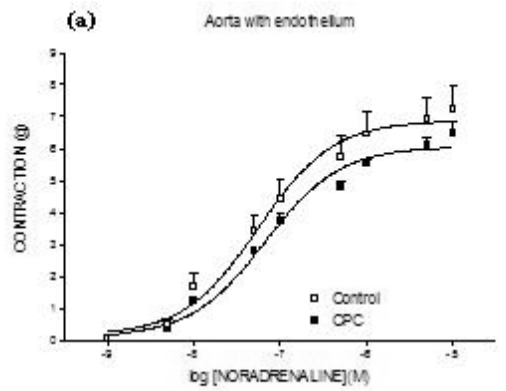

(c)

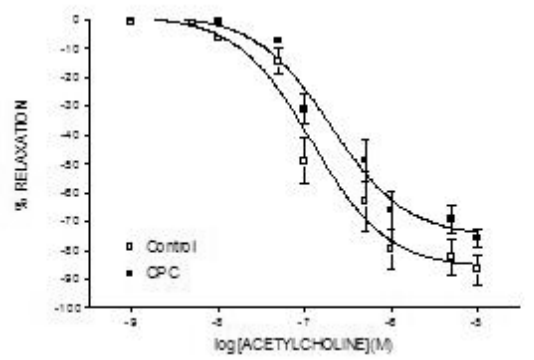

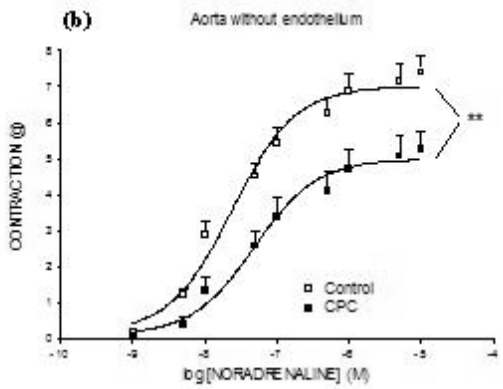

(d)
Fig. 3. Effect of Cognac polyphenolic compounds (CPC) treatment on vascular reactivity. Concentrationresponse curves to noradrenaline in aorta with (a) and without (b) endothelium taken from control $(\square)$ and CPC $(\mathbf{})$ treated rats. ${ }^{*} * P<0.01$ Control vs CPC-treated rats. (c) Concentration-response curves to acetylcholine in aortic rings precontracted with noradrenaline with endothelium from control and CPC-treated rats. (d) NO content of aorta measured by EPR in control ( $\square$; $n=5)$ and CPC-treated rats $(\boldsymbol{\square} ; n=5)$. Data are presented as mean \pm S.E.M. $n$ represents the number of rats. treated rats compared to those from rats receiving vehicle (Fig. 2b). Finally, heart NO content measured by EPR technique was not significantly different between the two groups of rats (Fig. 2c).

\section{Ex vivo vascular reactivity of aorta after CPC treatment}

Noradrenaline produced concentration-dependent contraction of aorta with or without endothelium from both control and CPC-treated groups (Fig. 3). The contractile response to noradrenaline was not significantly different in aorta from control and CPC-treated rats in the presence of functional endothelium (Fig. 3a). However, CPC treatment significantly reduced noradrenaline-induced contraction in the absence of functional endothelium ( $\mathrm{P}<0.01$; Fig. 3b). Acetylcholine produced a concentration-dependent relaxation in aorta with functional endothelium from both control and CPC-treated groups. Acetylcholine-induced relaxation was not significantly different in aortic rings from CPC-treated rats when compared with those from control group (Fig. 3c). In the absence of endothelium, acetylcholine failed to produce any relaxation response both in aortic rings from control and CPC-treated group (not shown). Finally, CPC treatment did not induce any significant change of basal aortic NO content (Fig. 3d).

\section{Discussion}

The present work showed that oral administration of $\mathrm{CPC}$ decreased platelet aggregation induced by ADP but not by collagen. CPC did not also affect adhesion to collagen. The chronotropic, but not the inotropic response to isoprenaline was reduced without any alteration of $\mathrm{NO}$ production in isolated hearts from CPC-treated rats when compared with those from control rats. CPC treatment did not affect ex vivo responses to the endothelial relaxant agent, acetylcholine, nor the NO content of rat aorta. Interestingly, CPC induced subtle modifications which maintain unchanged agonist-induced contractility in the aorta as a result of participation of endothelial vasoconstrictor products which compensate the effects of vasodilator compounds, the nature of which remains to be determined. Thus, the in vivo effects of CPC with antiplatelet activity and its capacity in decreasing heart overload during chronotropic stress may be beneficial for preventing some cardiovascular diseases.

We have recently reported that in vitro, $\mathrm{CPC}$ had endothelial NO-dependent vasorelaxant effects and stimulated cardiac function. In addition, oral treatment of rats with $\mathrm{CPC}$ at $40 \mathrm{mg} \mathrm{kg}^{-1}$ day $^{-1}$ for 2 weeks appeared to have no impact on blood pressure, heart rate or cardiac contractility ex vivo; however, it could decrease the infarct size after ischemia-reperfusion (Ralay Ranaivo et al. 2004). Indeed, we found that CPC possess antiplatelet properties and decrease inotropic effect to isoprenaline. CPC dose used in this study $\left(80 \mathrm{mg} \mathrm{kg}^{-1}\right)$ represents a large dose and is not relevant in terms of Cognac consumption (i.e. CPC plus alcohol). It should be 
noted that oral treatment of rats with CPC at $40 \mathrm{mg}$ $\mathrm{kg}^{-1}$ day $^{-1}$ for 2 weeks had no effect of ADP-induced platelet aggregation. Thus, higher dose of CPC and longterm treatment of CPC might be needed to affect the aggregation process. These differences require further investigation. However, the nature of polyphenols involved in the reported effect of in vivo CPC treatment is not known and it is out of the concern of the present work. Polyphenols found in CPC include mainly ellagic acid but also some phenolic acids (vanillic acid and gallic acid), furans and cinnamaldehydes (coniferaldehyde and sinapaldehyde). Ellagic acid has been found to possess antioxidant capacity and probably participate in part to the reported effect of oral CPC. Further studies are needed to identify the active components of CPC that produce the effects on both platelets and heart.

One of the novel findings of the present work was that CPC treatment reduced percentage and rate of ADP-induced aggregation, but it did not affect the same parameters and adhesion when collagen was used. These results suggest that CPC could not interfere with direct interaction between collagen and platelets, but they may lead to a decrease of aggregation induced by an agonist acting on either a specific receptor such as P2Y-receptors or shape-change process. Decrease in platelet aggregation is thought to be one of the mechanisms underlying the favorable effects of polyphenols in the prevention of coronary heart disease. These findings are in agreement with the others reported for Armagnac extract in rat arteriovenous shunt thrombosis model or in vitro treatments of human platelets (Umar et al. 2003, 2005). The precise composition of Armagnac extract is not known in these studies. It contains neither quercetin nor resveratrol, but it does contain polyphenol derivatives of ellagic acid such as those found in CPC. Thus, one can advance the hypothesis that ellagic acid might participate in the anti-platelets effect of CPC.Polyphenols have been shown to inhibit platelet function in vitro and in vivo (Hubbard et al. 2003). In particular, certain flavonoids have been shown to inhibit the generation of metabolites of arachidonic acid by cyclooxygenase and lipoxygenase (Beretz et al. 1982, You et al. 1999), and inhibit $\mathrm{Ca}^{2+}$ dependent isoforms of protein kinase C (Liu et al. 2000). Multiple signaling pathways controlled platelet functions and the exact mechanism of action has not been fully elucidated yet.

CPC administration has been reported to be able to reduce the infarct size after an ischemia-reperfusion injury, without affecting basal cardiovascular parameters of the rats (Ralay Ranaivo et al. 2004). In the present study, we extend the observation of CPC treatment on cardiac reactivity to the full $\beta$-adrenoceptor agonist isoprenaline and found that it did not affect the inotropic effect of this agonist but interestingly reduced its chronotropic property. Thus, CPC could decrease the heart-work by its moderate bradycardial effect after isoprenaline administration; this effect could be related to the capacity of CPC to preserve a good oxygen supply/demand balance after stimuli. Moreover, this effect might partly explain the ability of CPC in decreasing infarct size measured in reperfused hearts ex vivo (Ralay Ranaivo et al. 2004). Indeed, cellular injury observed after ischemia-reperfusion is mainly attributable not only to the development of a reperfusioninduced oxidative stress but also to disturbances of ionic homeostasis (for review see Park 1999).

Turning now to the effect of CPC treatment on vascular reactivity in response to a vasoconstrictor agonist, we note that the contractions to phenylephrine were unchanged by $\mathrm{CPC}$ in aortas with functional endothelium. In endothelium-denuded aortic rings from CPC-treated rats, the phenylephrine-induced contraction was decreased. Even though the nature of this hyporeactivity is not known, it is compensated by vasoconstrictor components from endothelial sources. Similar observations have been reported for oral treatment with RWPC, although the nature of polyphenols present in both extracts is different. Indeed, it was found that RWPC treatment is associated with a subtle balance between extra-endothelial NO production, inducing vascular hyporeactivity, and increased release from endothelium of COX-dependent vasoconstrictor molecules in the aortic wall (Diebolt et al. 2001). However, it should be noted that CPC treatment was not able to increase NO production within the aorta.

Finally, we found that acetylcholine-induced relaxation was not affected in aortas taken from CPCtreated rats in vivo. Furthermore, as reported above, CPC treatment failed to modify NO production within the aorta. These results contrast with data obtained in vitro in which CPC induced endothelium-dependent relaxation sensitive to NO synthase inhibitor. The reasons of the different observations might be multiple. Firstly, the polyphenols contained in CPC that produce endothelial NO vasodilatation might not be absorbed and reached the circulation in a sufficient amount in vivo. Secondly, as discussed above, CPC treatment stimulated the release of vasoconstrictor products that may mask an increase in 
endothelial relaxation.

In summary, we provide evidence that oral administration of CPC inhibits platelet aggregation mediated by ADP, reduces the chronotropic property of isoprenaline and induces subtle effects on vascular reactivity. This is independent from the alcohol content of Cognac. In addition to our previous studies showing that CPC treatment reduced the infarct size after an ischemiareperfusion injury, the results of present study strengthen the hypothesis that CPC may decrease the risk of coronary artery disease.

\section{Conflict of Interest}

There is no conflict of interest.

\section{Acknowledgements}

This work is partly supported by INSERM 771 and CNRS 6214.

\section{References}

ALENCAR JL, LOBYSHEVA I, CHALUPSKY K, GEFFARD M, NEPVEU F, STOCLET JC, MULLER B: $S$ Nitrosating nitric oxide donors induce long-lasting inhibition of contraction in isolated arteries. J Pharmacol Exp Ther 307: 152-159, 2003.

ANDRIAMBELOSON E, KLESCHYOV AL, MULLER B, BERETZ A, STOCLET JC, ANDRIANTSITOHAINA R: Nitric oxide production and endothelium-dependent vasorelaxation induced by wine polyphenols in rat aorta. Br J Pharmacol 120: 1053-1058, 1997.

ANDRIAMBELOSON E, MAGNIER C, HAAN-ARCHIPOFF G, LOBSTEIN A, ANTON R, BERETZ A, STOCLET JC, ANDRIANTSITOHAINA R: Natural dietary polyphenolic compounds cause endothelium-dependent vasorelaxation in rat thoracic aorta. $J$ Nutr 128: 2324-2333, 1998.

BERETZ A, CAZENAVE JP, ANTON R: Inhibition of aggregation and secretion of human-platelets by quercetin and other flavonoids - structure activity relationships. Agents Actions 12: 382-387, 1982.

CARANDO S, TEISSEDRE P-L, FERRIERE M, DESCOMPS B, CABANIS J-C: Athérosclérose: Physiopathologie. Boissons alcoolisées et cardiopathies ischémiques, in: Masson, Cahier de nutrition et de diététique. Société de nutrition et de dietetique de langue française (SNDLF). 1998, pp. 182-187.

CAZENAVE JP, HEMMENDINGER S, BERETZ A, SUTTER-BAY A, LAUNAY J: L'agrégation plaquettaire: outil d'investigation clinique et d'étude pharmacologique. Méthodologie. Ann Biol Clin 41: 167-179, 1983.

CURIN Y, ANDRIANTSITOHAINA R: Polyphenols as potential therapeutical agents against cardiovascular diseases. Pharmacol Rep 57 (Suppl): 97-107, 2005.

DA PORTO C, CALLIGARIS S, CELOTTI E, NICOLI MC: Antiradical properties of commercial cognacs assessed by the DPPH(.) test. J Agric Food Chem 48: 4241-4245, 2000.

DIEBOLT M, BUCHER B, ANDRIANTSITOHAINA R: Wine polyphenols decrease blood pressure, improve NO vasodilatation, and induce gene expression. Hypertension 38: 159-165, 2001.

GOLDBERG DM, HOFFMAN B, YANG J, SOLEAS GJ: Phenolic constituents, furans, and total antioxidant status of distilled spirits. J Agric Food Chem 47: 3978-3985, 1999.

GYORGY K, MULLER B, VEGH A, KLESCHYOV AL, STOCLET JC: Triggering role of nitric oxide in the delayed protective effect of monophosphoryl lipid A in rat heart. Br J Pharmacol 127: 1892-1898, 1999.

HUBBARD GP, WOLFFRAM S, LOVEGROVE JA, GIBBINS JM: The role of polyphenolic compounds in the diet as inhibitors of platelet function. Proc Nutr Soc 62: 469-78, 2003.

JOSEPHY PD, LORD HL, SNIECKUS VA: Inhibition of benzo[a]pyrene dihydrodiol epoxide mutagenicity by synthetic analogues of ellagic acid. Mutat Res 242 143-149, 1990.

KLESCHYOV AL, MOLLNAU H, OELZE M, MEINERTZ T, HUANG Y, HARRISON DG, MUNZEL T: Spin trapping of vascular nitric oxide using colloid Fe (II)-diethyldithiocarbamate. Biochem Biophys Res Commun 275: 672-677, 2000.

LIU W, LIANG NC: Inhibitory effect of disodium quercetin-7, 4-disulfate on aggregation of pig platelets induced by thrombin and its mechanism. Acta Pharmacol Sin 21: 737-741, 2000.

MAJID S., KHANDUJA KL, GANDHI RK, KAPUR S, SHARMA RR: Influence of ellagic acid on antioxidant defense system and lipid peroxidation in mice. Biochem Pharmacol 42: 1441-1445, 1991. 
PARK JW: Interventional cardiology versus minimally invasive cardiac surgery. Eur J Cardiothorac Surg 16 (Suppl 2): S117-S118, 1999.

PECHÁŇOVÁ O, BERNÁTOVÁ I, BABÁL P, MARTINEZ MC, KYSELÁ S, ŠTVRTINA S, ANDRIANTSITOHAINA R: Red wine polyphenols prevent cardiovascular alterations in L-NAME-induced hypertension. J Hypertens 22: 1551-1559, 2004.

PEREZ-VIZCAINO F, DUARTE J, ANDRIANTSITOHAINA R: Endothelial function and cardiovascular disease: Effects of quercetin and wine polyphenols Free Radic Res 40: 1054-1065, 2006.

RALAY RANAIVO H, DIEBOLT M, SCHOTT C, ANDRIANTSITOHAINA R: Polyphenolic compounds from Cognac induce vasorelaxation in vitro and decrease post-ischaemic cardiac infarction after an oral administration. Fundam Clin Pharmacol 18: 331-338, 2004.

RENAUD S, DE LORGERIL M: Wine, alcohol, platelets, and the French paradox for coronary heart disease. Lancet 339: 1523-1526, 1992.

RIMM EB, GIOVANNUCCI EL, WILLETT WC, COLDITZ GA, ASCHERIO A, ROSNER B, STAMPFER MJ: Prospective study of alcohol consumption and risk of coronary disease in men. Lancet 338: 464-468, 1991.

ROTONDO S, DE GAETANO G: Protection from cardiovascular disease by wine and its derived products. Epidemiological evidence and biological mechanisms. World Rev Nutr Diet 87: 90-113, 2000.

UMAR A, GUERIN V, RENARD M, BOISSEAU M, GARREAU C, BEGAUD B, MOLIMARD M, MOORE N: Effects of armagnac extracts on human platelet function in vitro and on rat arteriovenous shunt thrombosis in vivo. Thromb Res 110: 135-140, 2003.

UMAR A, DEPONT F, JACQUET A, LIGNOT S, SEGUR MC, BOISSEAU M, BEGAUD B, MOORE N: Effects of armagnac or vodka on platelet aggregation in healthy volunteers: a randomized controlled clinical trial. Thromb Res 115: 31-37, 2005.

YOU KM, JONG HG, KIM HP: Inhibition of cyclooxygenase/lipoxygenase from human platelets by polyhydroxylated/ methoxylated flavonoids isolated from medicinal plants. Arch Pharm Res 22: 18-24, 1999.

VITA JA: Polyphenols and cardiovascular disease: effects on endothelial and platelet function. Am J Clin Nutr 81: 292S-297S, 2005. 